\title{
Elevated serum levels of vascular endothelial growth factor is effective as a marker for malnutrition and inflammation in patients with ovarian cancer
}

\author{
TAKAFUMI WATANABE ${ }^{1}$, MASAHIKO SHIBATA ${ }^{2,3}$, HIROSHI NISHIYAMA ${ }^{1}$, SHU SOEDA ${ }^{1}$, \\ SHIGENORI FURUKAWA ${ }^{1}$, KENJI GONDA ${ }^{3,4}$, SEIICHI TAKENOSHITA ${ }^{3}$ and KEIYA FUJIMORI ${ }^{1}$ \\ Departments of ${ }^{1}$ Obstetrics and Gynecology, ${ }^{2}$ Tumor and Host Bioscience, ${ }^{3}$ Organ Regulatory Surgery \\ and ${ }^{4}$ Blood Transfusion and Transplantation Immunology, Fukushima Medical University, \\ Fukushima, Fukushima 960-1295, Japan
}

Received November 27, 2012; Accepted December 19, 2012

DOI: $10.3892 /$ br.2013.54

\begin{abstract}
Vascular endothelial growth factor (VEGF) reportedly plays an important role in the progression of malignant neoplasms. In the present study, measured serum concentrations of VEGF were measured in patients with ovarian cancer and correlations with nutritional damage and chronic inflammation were analyzed. A significant increase in serum levels in patients compared to healthy volunteers was observed. Levels of VEGF were inversely correlated with serum concentrations of prealbumin, transferrin and retinol-binding protein. VEGF levels were also correlated with serum levels of c-reactive protein (CRP), an effective marker of inflammation. CRP levels were significantly elevated in patients with stage III and IV disease and inversely correlated with serum concentrations of total protein, prealbumin, transferrin and retinol-binding protein. These results demonstrated that an increased production of VEGF correlated with nutritional impairment and inflammation.
\end{abstract}

\section{Introduction}

Ovarian cancer is the most frequent cause of death from gynecological cancer and the fourth most frequent cause of cancer-related death in women worldwide (1). Vascular endothelial growth factor (VEGF) plays a crucial role through its involvement in ovarian biology. Since it is closely associated with the normal function of ovaries, VEGF is also involved in ovarian pathologies, including malignant neoplasms (2). The observation that angiogenesis occurs around a neoplastic tumor was made over a century ago (3). Tumor growth and metastasis

Correspondence to: Dr Masahiko Shibata, Department of Tumor and Host Bioscience, Fukushima Medical University, 1 Hikarigaoka, Fukushima, Fukushima 960-1295, Japan

E-mail: mshibata@fmu.ac.jp

Key words: vascular endothelial growth factor, cachexia, ovarian cancer, nutritional damage were subsequently suggested to depend on angiogenesis and blockage of angiogenesis may thus provide one strategy for inhibiting tumor growth. The participation of angiogenesis and VEGF in the pathogenesis of neoplastic diseases has been previously described (4).

VEGF, previously known as vascular permeability factor, has a mass of $45 \mathrm{kDa}$ and belongs to a family of platelet-derived growth factors. Thus far, several forms of VEGF have been distinguished, including isoforms A, B, C, D and E $(5,6)$. The biological significance of the different forms of VEGF has yet to be definitively determined. Elevated VEGF levels are reportedly associated with advanced-stage melanoma, together with negative immune reactions, including type 2 helper T-cell (Th2) dominance and impaired dendritic cell function (7). Recent studies have reported that immune-suppressing myeloid cells that in increase in number in cancer are expandable by VEGF $(8,9)$.

Cachexia due to cancer is a complex metabolic disorder that includes loss of adipose tissue due to lipolysis, loss of skeletal muscle, elevation of resting energy consumption, anorexia and reduction of oral food intake (10). Acute-phase response proteins including VEGF are reportedly associated with the development of cachexia in patients with cancer (11). The present study investigated the status of VEGF and examined relationships in patients with ovarian cancer between serum levels of VEGF and markers of nutrition and inflammation.

\section{Materials and methods}

Sample collection. Blood samples were collected from 27 patients with ovarian cancer. The patient group included 4 patients with stage I disease, 2 with stage II, 13 with stage III and 8 with stage IV disease. The enrolled patients had received surgery or chemotherapy in the Department of Obstetrics and Gynecology at Fukushima Medical University Hospital (Fukushima, Japan) between May, 2011 and August, 2012 and were 38-83 years old (median, 58.5 years) with histological confirmation of the diagnosis. The patients were newly diagnosed and blood samples were collected prior to initiation of any treatment. 


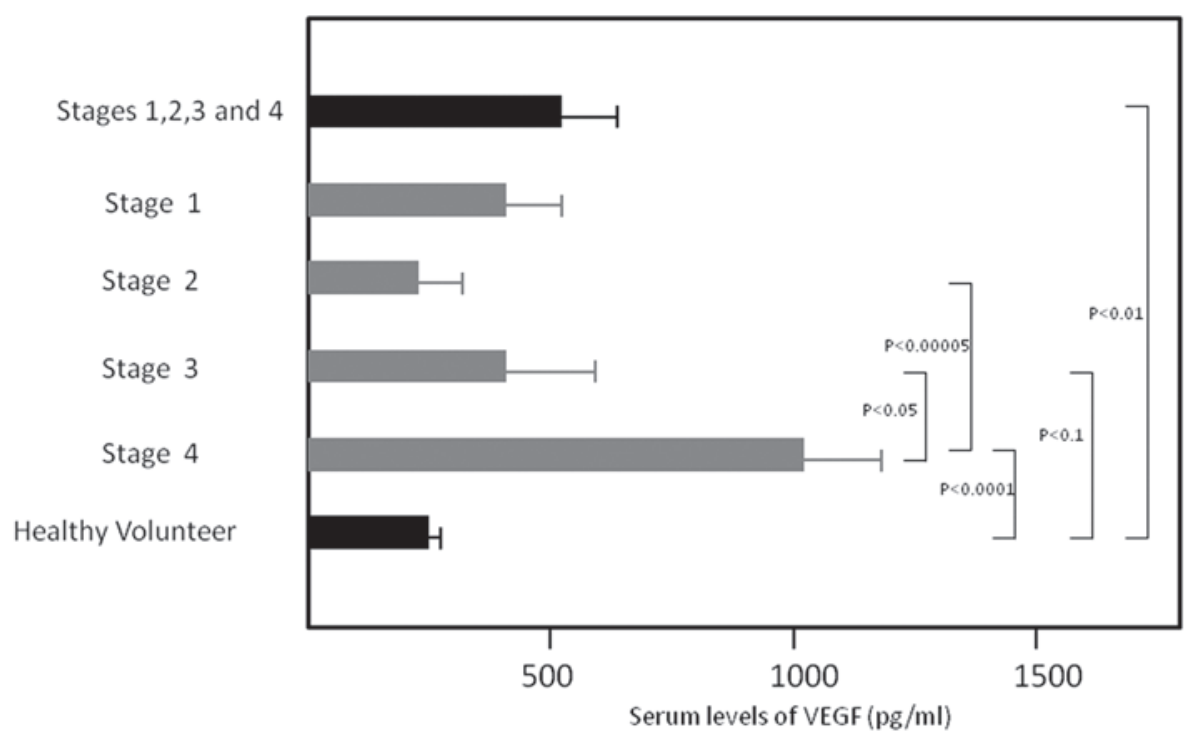

Figure 1. Serum vascular endothelial growth factor (VEGF) concentrations in patients with ovarian cancer. The serum levels of VEGF in whole patients, stage I, II, III and IV patients were $576.7 \pm 110.6,460.1 \pm 176.9,248.3 \pm 61.6,440.6 \pm 160.9$ and $1006.3 \pm 218.3 \mathrm{pg} / \mathrm{ml}$. Serum levels for whole patients $(\mathrm{P}<0.01)$ and stage IV patients $(\mathrm{P}<0.0001)$ were significantly increased as compared to healthy volunteers $(238.5 \pm 27.5 \mathrm{pg} / \mathrm{ml})$.

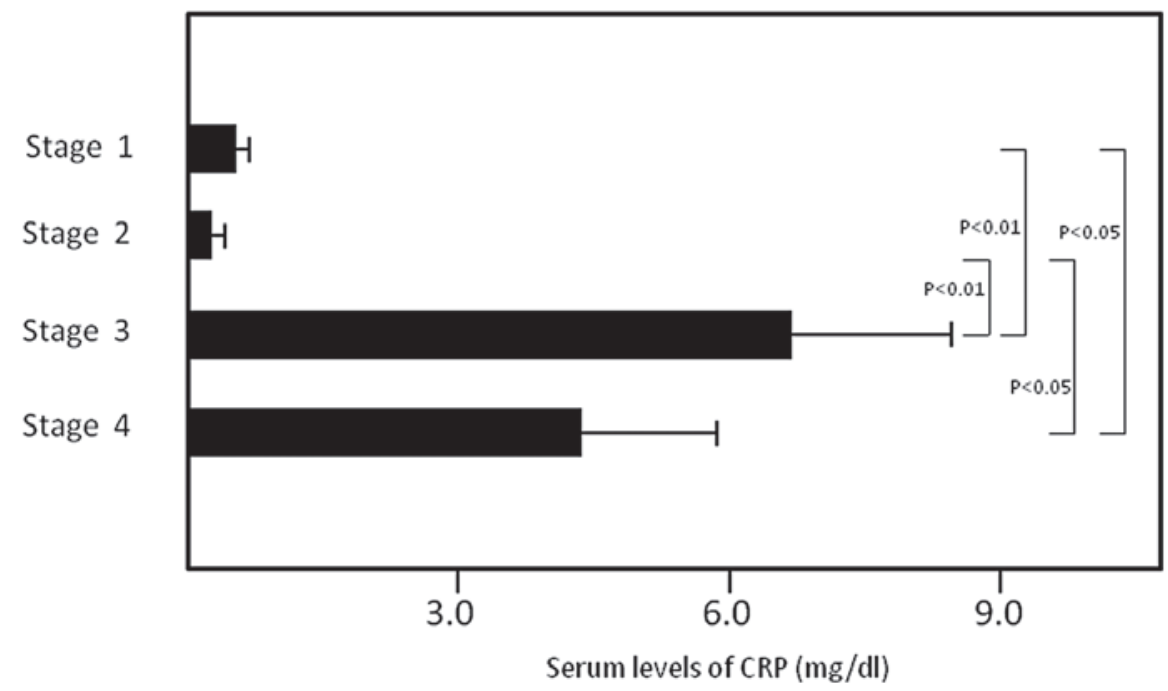

Figure 2. Serum c-reactive protein (CRP) concentrations in patients with ovarian cancer. The serum levels of CRP in stage I, II, III and IV patients were $0.64 \pm 0.04,0.34 \pm 0.27,6.76 \pm 1.76$ and $4.15 \pm 1.92 \mathrm{mg} / \mathrm{dl}$. Serum levels were significantly increased for stage III as compared to stage I (P<0.01) and stage II $(\mathrm{P}<0.01)$ patients, and for stage IV patients as compared to stage I $(\mathrm{P}<0.05)$ and stage II $(\mathrm{P}<0.05)$ patients.

This study was approved by the ethics committee at Fukushima Medical University (2010-2014) and written informed consent was obtained from the subjects enrolled in this study.

Serum levels of VEGF. Peripheral venous blood sera from the subjects were stored at $-80^{\circ} \mathrm{C}$ until use. Serum concentrations of VEGF were measured by enzyme-linked immunosorbent assay (ELISA) (R\&D Systems, Minneapolis, MN, USA) according to the manufacturer's instructions.

Markers for nutritional status. Nutritional status was determined by measuring serum concentrations of albumin (nephelometry), prealbumin (turbidimetric immunoassay), retinol-binding protein (latex agglutination immunoassay) and transferrin (turbidimetric immunoassay).

Statistical analysis. Differences between groups were determined using the Student's t-test. Relationships between two variables were quantified by the Spearman's rank correlation coefficient. $\mathrm{P}<0.05$ was considered statistically significant. Notably, not all the blood samples were of sufficient volume for the measurements.

\section{Results}

We tested sera from 27 patients with ovarian cancer and from 18 healthy volunteers. The serum levels of VEGF in whole 
A

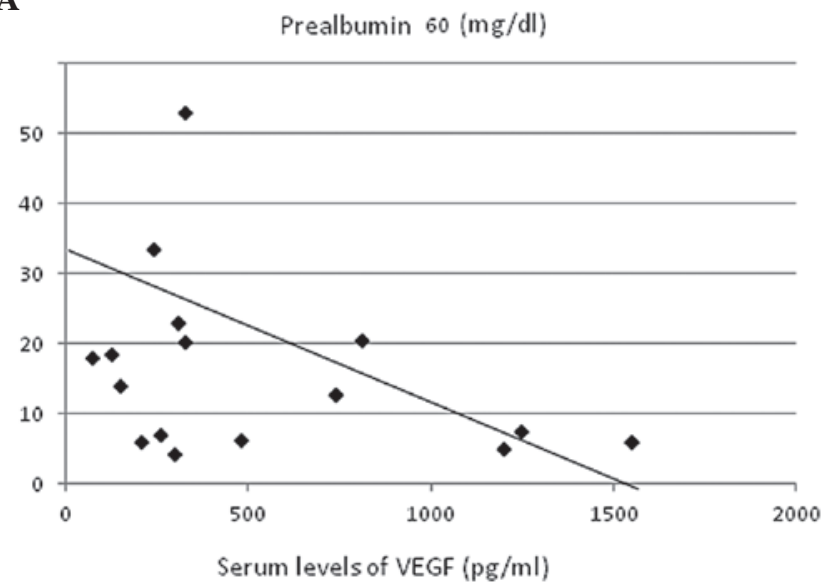

B

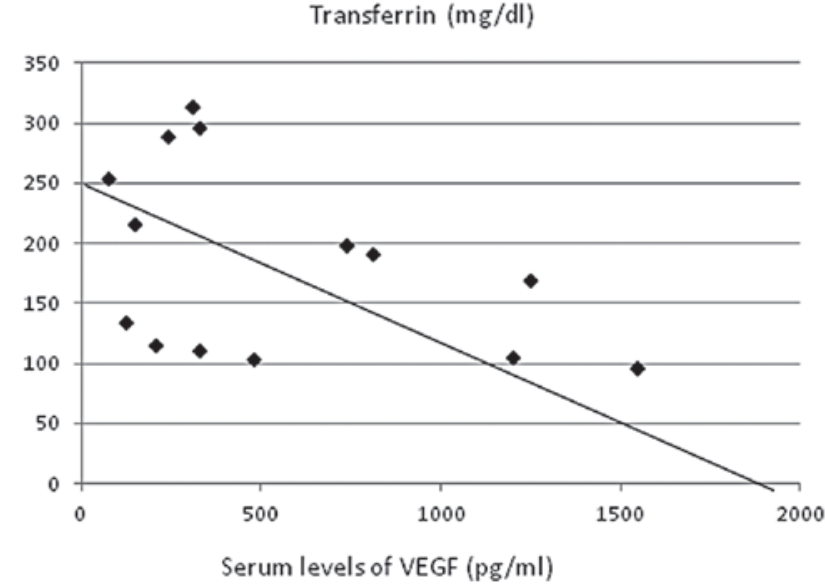

C

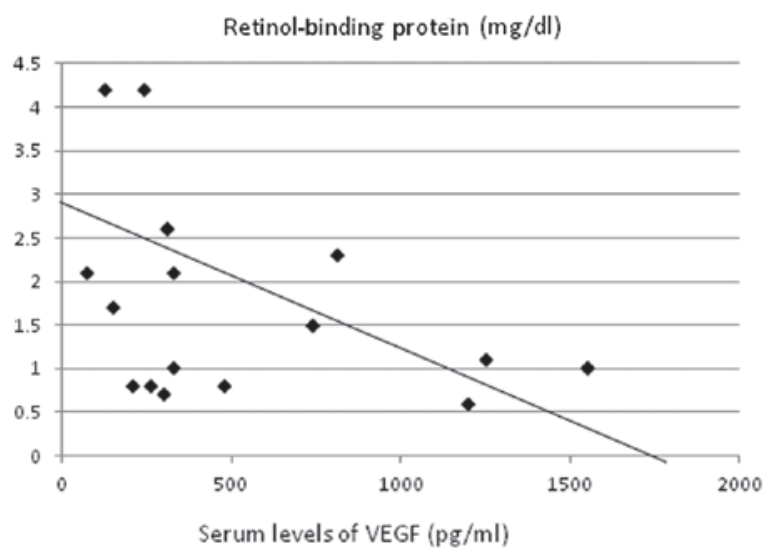

Figure 3. Correlation of serum levels of vascular endothelial growth factor (VEGF) with nutritional markers in ovarian cancer. VEGF levels showed significant inverse correlations with serum concentrations of (A) prealbumin $(\mathrm{r}=-0.467, \mathrm{P}<0.005),(\mathrm{B})$ transferrin $(\mathrm{r}=-0.640, \mathrm{P}<0.00005)$ and $(\mathrm{C}) \mathrm{ret}-$ inol-binding protein $(r=-0.457, \mathrm{P}<0.005)$.

patients, stage I, II, III and IV patients were 576.7 \pm 110.6 , $460.1 \pm 176.9,248.3 \pm 61.6,440.6 \pm 160.9$ and $1006.3 \pm 218.3 \mathrm{pg} / \mathrm{ml}$. Serum levels were significantly increased for whole patients $(\mathrm{P}<0.01)$ and stage IV patients $(\mathrm{P}<0.0001)$ compared to healthy volunteers $(238.5 \pm 27.5 \mathrm{pg} / \mathrm{ml})$ (Fig. 1). Serum levels of stage IV patients were significantly higher compared to those

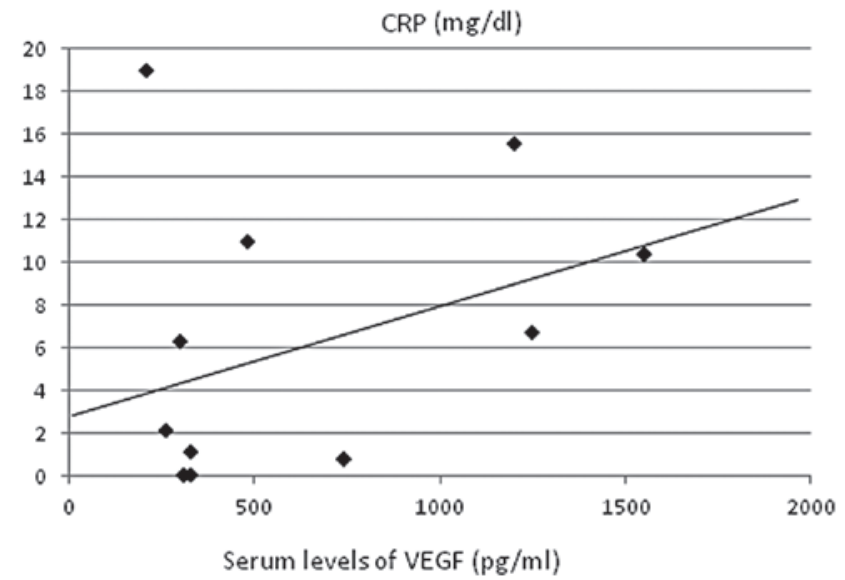

Figure 4. Correlation of serum vascular endothelial growth factor (VEGF) levels with c-reactive protein (CRP) in ovarian cancer. A strong positive correlation was detected between VEGF and CRP levels $(r=0.422, \mathrm{P}<0.01)$

of stage II $(\mathrm{P}<0.00005)$ and stage III $(\mathrm{P}<0.05)$ patients. The serum levels of CRP in stage I, II, III and IV patients were $0.64 \pm 0.04,0.34 \pm 0.27,6.76 \pm 1.76$ and $4.15 \pm 1.92 \mathrm{mg} / \mathrm{dl}$, with significant increases being detected in the serum levels for stage III compared to stage I $(\mathrm{P}<0.01)$ and stage II $(\mathrm{P}<0.01)$ patients, and for stage IV patients compared to stage I $(\mathrm{P}<0.05)$ and stage II $(\mathrm{P}<0.05)$ patients (Fig. 2).

These data were analyzed for correlations with parameters of nutritional status and inflammation. VEGF levels showed significant inverse correlations with serum concentrations of prealbumin ( $\mathrm{r}=-0.467, \mathrm{P}<0.005$; Fig. $3 \mathrm{~A})$, transferrin ( $\mathrm{r}=-0.640$, $\mathrm{P}<0.00005$; Fig. 3B) and retinol-binding protein $(\mathrm{r}=-0.457$, $\mathrm{P}<0.005$; Fig. 3C). A strong positive correlation was identified with CRP ( $\mathrm{r}=0.422, \mathrm{P}<0.01$; Fig. 4) and CRP levels showed significant inverse correlations with serum concentrations of total protein ( $\mathrm{r}=-0.402, \mathrm{P}<0.05$; Fig. 5A), albumin $(\mathrm{r}=-0.668$, $\mathrm{P}<0.0005$; Fig. 5B), prealbumin ( $\mathrm{r}=-0.511, \mathrm{P}=0.005$; Fig 5C), transferrin $(\mathrm{r}=-0.623, \mathrm{P}<0.0005$; Fig. 5D) and retinol-binding protein $(r=-0.410, \mathrm{P}<0.05$; Fig. $5 \mathrm{E})$.

\section{Discussion}

VEGF is important in the progression of malignant neoplasms (12). In the present study, we investigated the association of VEGF with nutritional damage and systemic inflammation. VEGF levels were significantly higher in patients with ovarian cancer than in healthy volunteers as well as in patients with stage IV patients. VEGF levels showed significant inverse correlations with nutritional status as reflected by prealbumin, transferrin and retinol-binding protein and the marker of inflammation, CRP, which has a strong association with nutritional damage. CRP levels were also significantly elevated in advanced diseases. These results strongly support the hypothesis that VEGF plays a significant role in malnutrition and inflammation, which are essential factors for the progression of ovarian cancer, supporting the possible involvement of VEGF in the pathogenesis of cachexia.

Decreased albumin concentrations are involved with cachexia and are common laboratory features in malignant 
A

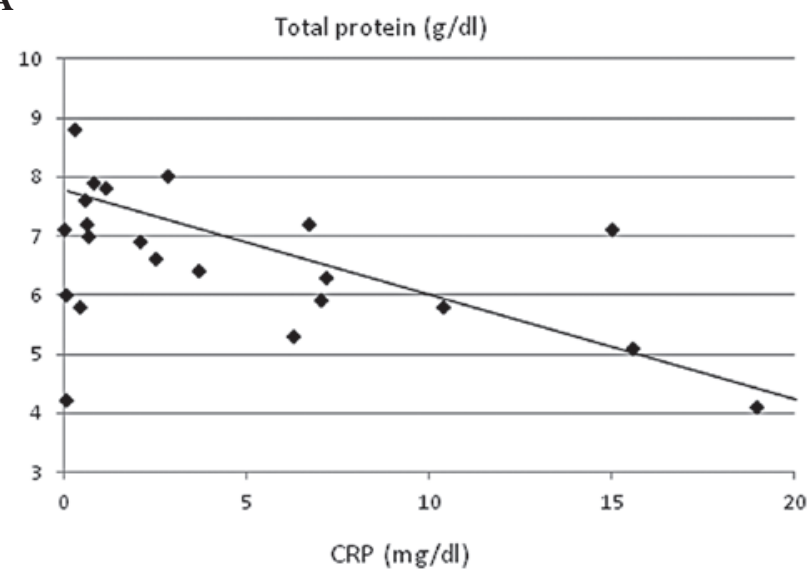

B

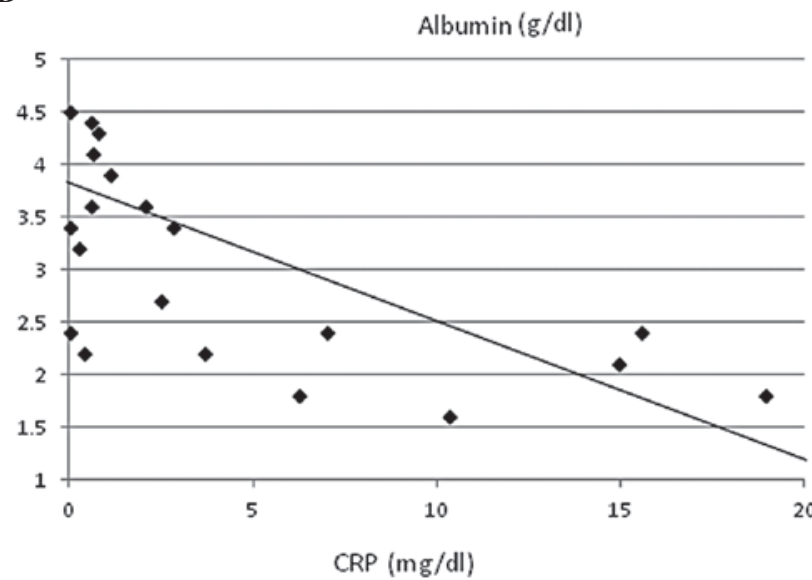

C

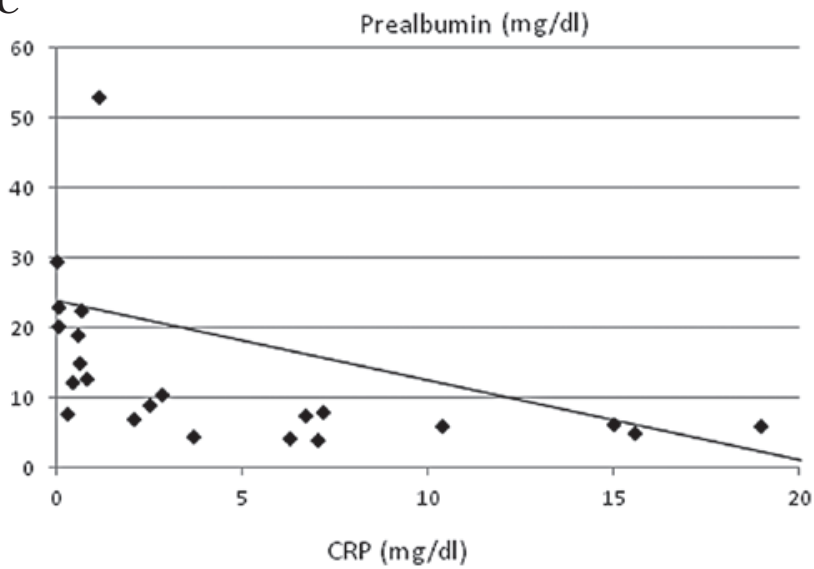

D

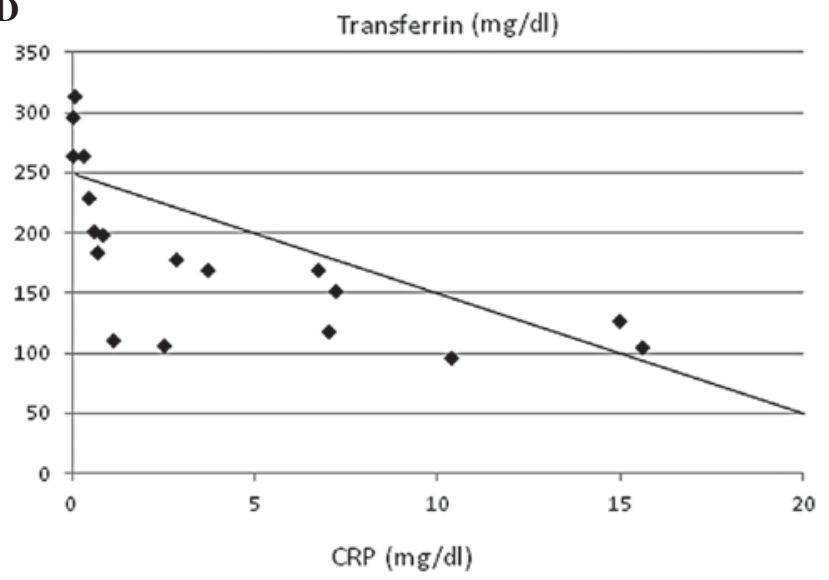

E

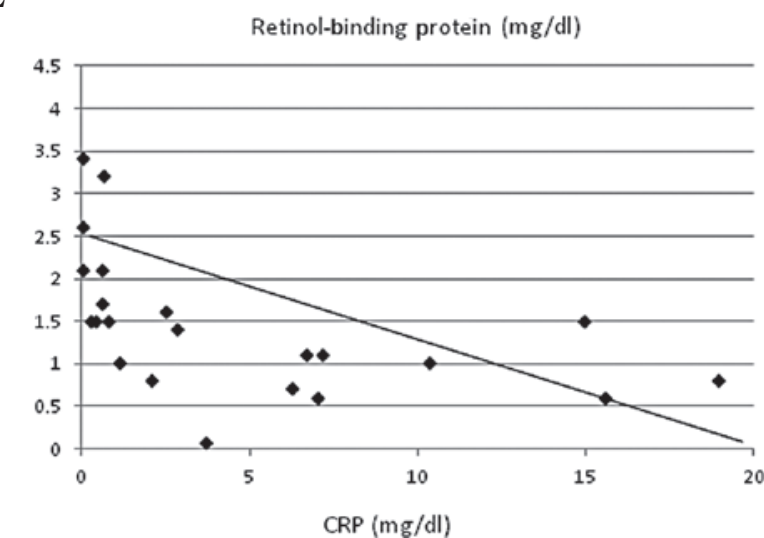

Figure 5. Correlation of serum c-reactive protein (CRP) levels with nutritional markers in ovarian cancer. CRP levels showed significant inverse correlations with serum concentrations of total protein $(A)(r=-0.402$, $\mathrm{P}<0.05)$, (B) albumin $(\mathrm{r}=-0.668, \mathrm{P}<0.0005)$, (C) prealbumin $(\mathrm{r}=-0.511$, $\mathrm{P}=0.005)$, (D) transferrin $(\mathrm{r}=-0.623, \mathrm{P}<0.0005)$ and $(\mathrm{E})$ retinol-binding protein $(r=-0.410, \mathrm{P}<0.05)$.

diseases. Hypoalbuminemia has been demonstrated to be a predictive factor for poor responsiveness $(13,14)$. The ongoing systemic inflammatory response in terms of CRP has recently gained some interest, as an easily measured and standardized predictor of outcomes in patients after treatment $(15,16)$.

The immunosuppressive properties of malignant tumors have been previously reported (17). Central to this hypothesis is the polarization of the immune system towards a state of inflammation driven by immunological mediators produced by tumor and immune cells $(17,18)$. CRP has been reported as a marker of systemic inflammatory response and an independent predictor of clinical benefit, good prognosis and survival in patients receiving cancer chemotherapy. We recently reported that myeloid-derived suppressor cells (MDSCs) are increased in various types of cancer $(19,20)$ and strong correlations of MDSC with malnutrition were identified in patients with digestive system cancer. Although the exact mechanisms involved in the increased production of immature myeloid cells in cancer patients remain unclear, it has been reported that VEGF is one of the key molecules involved in the induction and expansion of MDSC (21-23). In conclusion, results of this study have demonstrated that an increased production of VEGF correlated with nutritional impairment and systemic inflammation. Future studies should be conducted to investigate possibilities for clinical control of chronic inflammation through the modulation of VEGF.

\section{Acknowledgements}

We would like to thank Dr Mineyuki Haruta, The Nihon University College of Engineering for processing ELISA data.

\section{References}

1. Jacobs IJ and Menon U: Progress and challenges in screening for early detection of ovarian cancer. Mol Cell Proteomics 3: 355-366, 2004.

2. Geva E and Jaffe RB: Role of vascular endothelial growth factor in ovarian physiology and pathology. Fertil Steril 74: 429-438, 2000. 
3. Goldman E: The growth of malignant disease in man and the lower animals with special reference to the vascular system. Proc R Soc Med 1: 1-13, 1908.

4. Folkman J: Angiogenesis in cancer, vascular, rheumatoid and other disease. Nat Med 1: 27-31, 1995.

5. Senger DR, Galli SJ, Dvorak AM, et al: Tumor cell secrete a vascular permeability factor that promotes accumulation of ascites fluid. Science 219: 983-985, 1983.

6 . Ferrara $\mathrm{N}$ : Vascular endothelial growth factor and the regulation of angiogenesis. Recent Prog Horm Res 55: 15-36, 2000.

7. Terheyden P, Schrama D, Pedersen LO, et al: Longitudinal analysis of MART-1/HLA-A2-reactive T cells over the course of melanoma progression. Scand J Immunol 58: 566-571, 2003.

8. Gabrilovich DI and Nagaraj S: Myeloid-derived suppressor cells as regulators of the immune system. Nat Rev Immunol 9 . 162-174, 2009.

9. Ostrand-Rosenberg S and Sinha P: Myeloid-derived suppressor cells: linking inflammation and cancer. J Immunol 182 4499-4506, 2009.

10. Rubin H: Cancer cachexia: its correlations and causes. Proc Natl Acad Sci USA 100: 5384-5389, 2003.

11. Deans C and Wigmore SJ: Systemic inflammation, cachexia and prognosis in patients with cancer. Curr Opin Clin Nutr Metab Care 8: 265-269, 2005.

12. Kajdaniuk D, Marek B, Foltyn W and Kos-Kudla B: Vascular endothelial growth factor (VEGF)-part 2: in endocrinology and oncology. Endocrinol Pol 62: 456-464, 2011.

13. Sanz L, Ovejero VJ, Gonzalez JJ, et al: Mortality risk scales in esophagotomy for cancer: their usefulness in preoperative patients selection. Hepatogastroenterology 53: 869-873, 2006.

14. Onate-Ocana LF, Aiello-Crocifoglio V, Gallardo-Rincon D, et al: Serum albumin as a significant prognostic factor for patients with gastric carcinoma. Ann Surg Oncol 14: 381-389, 2007.

15. Chua W, Charles KA, Baracos VE and Clarke SJ: Neutrophil/lymphocyte ratio predicts chemotherapy outcomes in patients with advanced colorectal cancer. Brit J Cancer 104: 1288-1295, 2011.
16. Cho H, Hur HW, Kim SW, et al: Pre-treatment neutrophil to lymphocyte ratio is elevated in epithelial ovarian cancer and predicts survival after treatment. Cancer Immunol Immunother 58: 15-23, 2009.

17. Nevala WK, Vachon CM, Leontovich AA, Scott CG Thompson MA and Markovic SN: Evidence of systemic Th2-driven chronic inflammation in patients with metastatic melanoma. Clin Cancer Res 15: 1931-1939, 2009.

18. Coussens LM and Werb Z: Inflammation and cancer. Nature 420 : 860-867, 2002

19. Shibata M, Shimura T, Gonda K, Suzuki S, Nakamura I, Ohki S and Takenoshita S: Relationship of myeloid-derived suppressor cells (MDSC) and immune suppression, nutritional impairment, and inflammatory markers in patients with gastrointestinal cancer. 2012 ASCO Gastrointestinal Cancer Symposium: ASCO abs. $675,2012$.

20. Ohki S, Shibata M, Gonda K, et al: Circulating myeloid-derived suppressor cells are increased and correlate to immune suppression, inflammation and hypoalbuminemia in patients with cancer. Oncol Rep 28: 453-458, 2012.

21. Gabrilovich DI, Chen HL, Girgis KR, et al: Production of vascular endothelial growth factor by human tumors inhibits the functional maturation of dendritic cells. Nat Med 2: 1096-1103, 1996.

22. Menetrier-Caux C, Montmain G, Dieu MC, et al: Inhibition of the differentiation of dendritic cells from CD34+ progenitors by tumor cells: role of interleukin-6 and macrophage-colony-stimulating factor. Blood 92: 4778-4791, 1998.

23. Gabrilovich D, Ishida T, Oyama T, et al: Vascular endothelial growth factor inhibits the development of dendritic cells and dramatically affects the differentiation of multiple hematopoietic lineages in vivo. Blood 92: 4150-4166, 1998. 